\title{
Factors predicting the development of urethral stricture after bipolar transurethral resection of the prostate
}

\author{
Faraj Afandiyev ${ }^{1 *} \odot$, Ozgur Ugurlu ${ }^{1} \oplus$
}

\begin{abstract}
SUMMARY
OBJECTIVE: We aimed to investigate the rate of urethral stricture development, predictor factors, and the reliability following bipolar transurethral resection of the prostate.

METHODS: A total of 124 patients participated in this study. Patient data were retrospectively reviewed. The patients were divided into group 1 (those who developed urethral stricture) and group 2 (those who did not develop urethral stricture). Annual checkups were performed after the postoperative months 1 and 6 . The patients were checked by uroflowmetry + post-voiding residue and international index of erectile function. We evaluated the complications that developed during the perioperative period according to the Clavien system.

RESULTS: Urethral stricture developed in 10.5\% (13/124) of the patients. It was found that patients who underwent transurethral resection of the prostate for the second time ( $p=0.007$ ), patients with a preoperative catheter or history of catheter insertion ( $p=0.009)$, patients with high preoperative median white blood cell $\left(10^{3}\right)$ counts $(p=0.013)$, and patients with long postoperative catheterization time had a higher rate of urethral stricture after bipolar transurethral resection of the prostate $(p=0.046)$. No grade 4 and grade 5 complications were observed according to the Clavien system in patients.

CONCLUSION: Factors such as second transurethral resection of the prostate surgery, history of preoperative catheter insertion, high postoperative white blood cell count, and long postoperative catheterization time increase the risk of urethral stricture after bipolar transurethral resection of the prostate.
\end{abstract}

KEYWORDS: Lower urinary tract symptoms. Urethral stricture. Prostate. Urinary tract infections.

\section{INTRODUCTION}

In bipolar transurethral resection of the prostate (BTURP), radio frequency energy creates a vapor (plasma) layer containing energy-charged particles around the electrode in a conductive environment, which causes the prostate tissue to be resected easily. In addition, this plasma area prevents the resected tissues from sticking to the electrode. The current from the active electrode passes to the adjacent return electrode without passing through the patient's body, which eliminates the need for diathermy pads. Isotonic $0.9 \%$ saline fluid is used as irrigation fluid in the bipolar method ${ }^{1,2}$. There are four different types of bipolar TUR devices developed and actively marketed today: Plasma kinetic technology (Gyrus-PK), AUTOCON II 400 ESU (Karl Storz Endoskope, Tuttlingen, Germany), TURis (Olympus, Tokyo, Japan), and Richard Wolf bipolar device.

There are many studies showing that BTURP is a successful and reliable method ${ }^{3,4}$. Although the rate of developing urethral stricture following BTURP (3.4-12.7\%) is not high ${ }^{11,12}$, it may cause serious complications such as urinary retention, acontractile bladder, urethral abscess, necrotizing fasciitis, and renal failure. Investigation of factors predicting the development of urethral stricture following BTURP may help prevent serious complications. Many investigators have reported the effect of several factors such as age, operation time, amount of removed prostate tissue, presence of urinary infection, and catheterization time on the development of urethral stricture following BTURP ${ }^{17-22}$. Literature review showed that there is no publication investigating the effect of preoperative white blood cell (WBC) count, having a preoperative catheter or history of preoperative catheter insertion, use of nonsteroidal anti-inflammatory drugs (NSAIDs), history of preoperative prostatitis, secondary surgery history, type of anesthesia applied (i.e., regional or general), and history of postoperative urinary retention on development of urethral stricture. In this study, we have investigated the effect of this and other factors on the development of urethral stricture after BTURP and the rate of urethral stricture development.

${ }^{1}$ Lokman Hekim University, Faculty of Medicine, Department of Urology - Ankara, Turkey.

${ }^{*}$ Corresponding author: ferecefendiyev@gmail.com

Conflicts of interest: the authors declare there is no conflicts of interest. Funding: none.

Received on October 15, 2021. Accepted on October 18, 2021. 


\section{METHODS}

Patients who underwent BTURP (Plasmakinetic) between January 2016 and January 2020 and who had no history of preoperative and intraoperative urethral stricture were included in this study. Patient data were collected retrospectively. A total of 128 patients participated in this study. Four of these patients were excluded from the study as they were applied TUR-P for palliative purposes due to prostate cancer. The patients were subjected to preoperative urine culture examination for urinary tract infection (UTI). A bacterial growth of $10^{5}$ colonies $/ \mathrm{ml}$ in urine culture was considered significant for UTI. The third-generation cephalosporin or quinolone group antibiotics were administered to all preoperative patients for prophylaxis. The patients were discharged on postoperative days 1 and 2. Postoperative checkups were performed with uroflowmetry + post voiding residue (PVR) and international prostate symptom score (IPSS) at month 1 , month 6 , and then annually. Patients who has $\mathrm{Q}_{\max }<15 \mathrm{ml} / \mathrm{s}$ according to the control uroflowmetry were suspected of urethral stricture, and the definitive diagnosis was made using endoscopy.

The patients were divided into two groups: group 1 (those who developed urethral stricture) and group 2 (those who did not develop urethral stricture). In our study, we investigated the relationship between the development of urethral stricture following BTURP and the presence of a preoperative catheter (indwelling Foley catheter) or a history of catheter (Foley catheter insertion for any reason) insertion, preoperative white blood cell (WBC) $\left(10^{3}\right)$ count, history of diabetes mellitus (DM), postoperative NSAID use, history of preoperative prostatitis (acute bacterial prostatitis), history of secondary BTURP surgery, type of anesthesia applied (i.e., regional or general), the presence of postoperative UTI, smoking, and development of postoperative urinary retention. In addition, we examined the effects of factors such as age, operation duration, prostate weight, amount of prostate tissue resected, and catheterization time, which were previously investigated in the literature, on the development of urethral stricture. We evaluated the complications that developed during the perioperative period according to the Clavien system.

\section{Statistical analyses}

Statistical analyses were performed using SPSS version 25 (IBM SPSS Corp., Armonk, NY, USA) software. The suitability of the variables for normal distribution was investigated using Kolmogorov-Smirnov and Shapiro-Wilk analytical methods. Descriptive statistical analyses were performed using the median and interquartile range for non-normally distributed variables. Independent-sample t-test was used for normally distributed independent variables, Mann-Whitney U-test for non-normally distributed independent variables, and chi-square and Fisher's exact tests were used to compare the categorical data. The results were considered statistically significant for cases where the p-value was $<0.05$ at a $95 \%$ confidence interval.

\section{RESULTS}

A total of 124 patients participated in this study. Urethral stricture developed in $10.5 \%(13 / 124)$ of the patients. The median age in group 1 and group 2 was $70.76 \pm 8.65$ and $74.46 \pm 8.7$ (mean $\pm S D)$, respectively. There was no statistical difference between the two groups $(\mathrm{p}=0.148)$. The number of patients with a preoperative diagnosis of prostatitis was 4 (3.2\%), and the number of secondary cases with a permanent catheter was $25(20.1 \%)$.

Notably, 46\% (6/13) of urethral strictures developed in the bulbar urethra, $38.5 \%(5 / 13)$ in the membranous urethra, and $16 \%(2 / 13)$ in the bladder neck.

The median preoperative WBC count was $7.30 \times 10^{3}(5.87$ $\left.\times 10^{3}-8.54 \times 10^{3}\right)$, the median operation time was $60 \mathrm{~min}$ (45-65), the median preoperative prostate volume was $57 \mathrm{ml}$ (39-80.75), the median prostate volume resected was $30 \mathrm{ml}$ (17.25-47), and the median postoperative catheterization time was 3.26 \pm 1.9 days (median \pm SD). In the postoperative period, 7 (5.6\%) patients developed urinary retention and 11 (8.8\%) patients developed UTI. The follow-up period was minimum 10 months and maximum 57 months (Table 1). The catheters were reinserted to patients who developed postoperative urinary retention and were removed after $48 \mathrm{~h}$. It was observed that all of these patients were able to urinate. Perioperative complications were evaluated using the Clavien system. We did not encounter any cases requiring blood transfusion and developing TUR syndrome. Clavien grade 4 and grade 5 complications were not observed in patients.

The demographic and clinical characteristics of patients with or without urethral stricture after BTURP were statistically evaluated. As a result, it was found that urethral stricture following BTURP developed more frequently in second BTURP ( $\mathrm{p}=0.007)$, history of catheter insertion $(\mathrm{p}=0.009)$, those with a high preoperative median WBC count $(\mathrm{p}=0.013)$, and those with a long postoperative catheterization period $(\mathrm{p}=0.046)($ Table 2).

In addition, we were not able to investigate the effect of the size and type of the resectoscope (monopolar/bipolar) and the catheter size on the development of urethral stricture as the 
Table 1. Demographic characteristics of 124 patients.

\begin{tabular}{|c|c|}
\hline Total number of patients & $(n=124 ; 100 \%)$ \\
\hline Mean age (years) $\pm S D$ & $71.15 \pm 7.69$ \\
\hline \multicolumn{2}{|l|}{ Preoperative prostatitis, n (\%) } \\
\hline Yes & $4(3.2)$ \\
\hline No & $120(96.8)$ \\
\hline \multicolumn{2}{|l|}{ Case status, n (\%) } \\
\hline Primary & $110(88.7)$ \\
\hline Secondary & $14(11.3)$ \\
\hline \multicolumn{2}{|l|}{ Preoperative catheter status, n (\%) } \\
\hline Catheter history not available & $28(22.5)$ \\
\hline Catheter history available & $71(57.2)$ \\
\hline With permanent catheter & $25(20.1)$ \\
\hline Median preoperative WBC $\left(10^{3}\right)$ (IQR) & $7.30(5.87-8.54)$ \\
\hline \multicolumn{2}{|l|}{ Diabetes mellitus, n (\%) } \\
\hline Yes & $36(29)$ \\
\hline No & $88(71)$ \\
\hline \multicolumn{2}{|l|}{ Smoking, n (\%) } \\
\hline Yes & $10(8)$ \\
\hline No & $114(92)$ \\
\hline Median operation time (min) (IQR) & $60(45-65)$ \\
\hline \multicolumn{2}{|l|}{ Anesthesia time (min), n (\%) } \\
\hline$<60$ & $8(6.4)$ \\
\hline$>60$ & $116(93.6)$ \\
\hline $\begin{array}{l}\text { Median preoperative prostate volume (ml) } \\
\text { (IQR) }\end{array}$ & $57(39-80.75)$ \\
\hline Median removed prostate volume (ml) (IQR) & $30(17.25-47)$ \\
\hline \multicolumn{2}{|l|}{ Perioperative NSAID use, n (\%) } \\
\hline Yes & $106(85.4)$ \\
\hline No & $18(14.6)$ \\
\hline \multicolumn{2}{|l|}{ Anesthesia type, n (\%) } \\
\hline Regional & $63(50.8)$ \\
\hline General & $61(49.2)$ \\
\hline $\begin{array}{l}\text { Mean postoperative catheterization time } \\
\text { (days) } \pm S D\end{array}$ & $3.26 \pm 1.9$ \\
\hline \multicolumn{2}{|l|}{ Postoperative urethral stricture, n (\%) } \\
\hline Yes & $13(10.5)$ \\
\hline No & $111(89.5)$ \\
\hline \multicolumn{2}{|l|}{ Postoperative retention presence, n (\%) } \\
\hline Yes & $7(5.6)$ \\
\hline No & $117(94.4)$ \\
\hline \multicolumn{2}{|l|}{ Postoperative UTI, n (\%) } \\
\hline Yes & $11(8.8)$ \\
\hline No & 113 (91.2) \\
\hline
\end{tabular}

IQR: interquartile range; UTI: urinary tract infection; SD: standard deviation; NSAID: nonsteroidal anti-inflammatory drug; WBC: white blood cell.
Table 2. Factors affecting the development of urethral stricture in patients undergoing bipolar transurethral resection of the prostate: (univariate analysis results).

\begin{tabular}{|c|c|c|c|}
\hline $\begin{array}{l}\text { Total number } \\
\text { of patients } \\
\text { ( } n=124 ; 100 \%)\end{array}$ & $\begin{array}{l}\text { No stricture } \\
\text { (n=111; } \\
89.5 \%)\end{array}$ & $\begin{array}{c}\text { Stricture } \\
(n=13 ; \\
10.5 \%)\end{array}$ & $\mathbf{p}^{*}$ \\
\hline Mean age $\pm S D$ & $70.76 \pm 8.65$ & $74.46 \pm 8.7$ & 0.148 \\
\hline \multicolumn{4}{|c|}{ Preoperative prostatitis, $\mathrm{n}(\%)$} \\
\hline Yes $(n=4)$ & $4(3.6)$ & - & \multirow{2}{*}{0.487} \\
\hline No $(n=120)$ & $107(96.4)$ & $13(100)$ & \\
\hline \multicolumn{4}{|l|}{ Case status, n (\%) } \\
\hline Primary $(n=110)$ & $102(91.9)$ & $8(61.5)$ & \multirow{2}{*}{$0.007^{*}$} \\
\hline Secondary $(n=14)$ & $9(8.1)$ & $5(38.5)$ & \\
\hline \multicolumn{4}{|c|}{ Preoperative catheter status, n (\%) } \\
\hline $\begin{array}{l}\text { Catheter history } \\
\text { not available }(n=28)\end{array}$ & $21(18.9)$ & $7(53.8)$ & \multirow{3}{*}{$0.009^{*}$} \\
\hline $\begin{array}{l}\text { Catheter history } \\
\text { available }(n=71)\end{array}$ & $65(52.6)$ & $6(46.2)$ & \\
\hline $\begin{array}{l}\text { With permanent } \\
\text { catheter }(n=25)\end{array}$ & $25(22.5)$ & - & \\
\hline $\begin{array}{l}\text { Median } \\
\text { preoperative WBC } \\
\left(10^{3}\right)(I Q R)\end{array}$ & $\begin{array}{c}6.03 \\
(5.11-7.57)\end{array}$ & $\begin{array}{c}7.38 \\
(5.91-8)\end{array}$ & $0.013^{*}$ \\
\hline DM presence, $\mathrm{n}(\%)$ & $33(29.7)$ & $3(23.1)$ & 0.445 \\
\hline Smoking & - & $10(9)$ & 0.316 \\
\hline $\begin{array}{l}\text { Median operation } \\
\text { time (min) (IQR) }\end{array}$ & $60(45-75)$ & $55(40-62.5)$ & 0.319 \\
\hline \multicolumn{4}{|c|}{ Anesthesia time (min), n (\%) } \\
\hline$<60(n=8)$ & $7(6.3)$ & $1(7.7)$ & \multirow{2}{*}{0.847} \\
\hline$>60(n=116)$ & $104(93.7)$ & $12(92.3)$ & \\
\hline $\begin{array}{l}\text { Median preoperative } \\
\text { prostate volume (ml) } \\
\text { (IQR) }\end{array}$ & $60(30-67.5)$ & $46(40-81)$ & 0.134 \\
\hline $\begin{array}{l}\text { Median removed } \\
\text { prostate volume }(\mathrm{ml}) \\
(\mathrm{IQR})\end{array}$ & $30(18-50)$ & $20(10-30)$ & 0.081 \\
\hline \multicolumn{4}{|c|}{ Perioperative NSAID, n (\%) } \\
\hline Yes $(n=106)$ & $95(85.6)$ & $11(84.6)$ & \multirow{2}{*}{0.925} \\
\hline No $(n=18)$ & $16(14.4)$ & $2(15.4)$ & \\
\hline \multicolumn{4}{|l|}{ Anesthesia type, n (\%) } \\
\hline Regional $(n=63)$ & $56(50.5)$ & $7(53.8)$ & \multirow{2}{*}{0.817} \\
\hline General $(n=61)$ & $55(49.5)$ & $6(46.2)$ & \\
\hline $\begin{array}{l}\text { Mean postoperative } \\
\text { catheterization time } \\
\text { (days) } \pm \text { SD }\end{array}$ & $5.15 \pm 1.67$ & $6.23 \pm 2.16$ & $0.046^{*}$ \\
\hline \multicolumn{4}{|c|}{ Postoperative retention presence, $\mathrm{n}(\%)$} \\
\hline Yes $(n=7)$ & $6(5.4)$ & $1(7.7)$ & \multirow{2}{*}{0.549} \\
\hline No $(n=117)$ & $105(94.6)$ & $12(92.3)$ & \\
\hline \multicolumn{4}{|l|}{ Postoperative UTI, n (\%) } \\
\hline Yes $(n=11)$ & $8(7.2)$ & $3(23.1)$ & \multirow{2}{*}{0.091} \\
\hline No $(n=113)$ & $103(92.8)$ & $10(76.9)$ & \\
\hline
\end{tabular}

${ }^{*}$ Chi-square test, Fisher's exact test, independent-samplet-test, Mann-Whitney U-test. IQR: interquartile range; DM: diabetes mellitus; UTI: urinary tract infection; SD: standard deviation; NSAID: nonsteroidal anti-inflammatory drug. 
"Storz" brand 26F bipolar resectoscope was used in all patients and a $20 \mathrm{~F}$ or $22 \mathrm{~F}$ three-way "Rusch" brand Foley urethral catheter was inserted to all patients at the end of the operation.

We could not find a statistically significant variable in the multivariate logistic regression analysis performed with variables that were found to be significant in the univariate analyses intended to determine independent risk factors affecting the development of postoperative urethral stricture.

\section{DISCUSSION}

Although BTURP is a successful method, it also brings about complications such as urethral stricture ${ }^{3,5}$. In this study, it was found that the rate of urethral stricture development following BTURP was $10.5 \%$. Sarier et al. showed in their study that renal transplantation did not increase the risk of urethral stricture and found that the rate of urethral stricture development following BTURP was $8.9-12.5 \%^{21,22}$. The rate of stricture following BTURP varies between $2 \%$ and $12.7 \%$ in different studies ${ }^{6,79}$. In this study, the median age of those with and without urethral stricture was similar. In many studies, it has been demonstrated that age does not have a statistically significant effect on the development of urethral stricture ${ }^{6,7,9}$.

We found no difference in the stricture risk in 4 (3.5\%) patients with preoperative UTI diagnosis compared to those without preoperative UTI. Tan et al. ${ }^{7}$ showed that preoperative UTI did not increase the risk of urethral stricture $(\mathrm{p}=0.717)$, while Aydemir et al. ${ }^{10}$ showed that preoperative UTI increased the risk of urethral stricture.

Tan et al. showed that the risk of urethral stricture did not increase significantly in patients who underwent BTURP for the second time $(1 / 13)(p=1.000)$. This study revealed that the risk of urethral stricture increased after the second BTURP operation (5/13) $(\mathrm{p}=0.007)$. In addition, Tan et al. ${ }^{7}$ observed that prolongation of the resection rate $(\mathrm{g} / \mathrm{min})$ increased the risk of urethral stricture. In this study, we did not calculate the resection rate separately, but we observed that there was no correlation between the amount of tissue resected and the duration of the operation and the development of urethral stricture. Kumar et al. ${ }^{9}$ did not examine the effect of this factor in their study. Komura et al. ${ }^{11}$ showed that the risk of urethral stricture increased in prostates over $70 \mathrm{~g}$.

In this study, we found that a long postoperative catheterization time increased the risk of urethral stricture ( $\mathrm{p}=0.045)$. Contrary to this study, many studies showed that prolongation of postoperative catheterization time did not increase the risk of urethral stricture ${ }^{7,9-11}$.
We observed that DM and smoking did not increase the risk of urethral stricture. Kumar et al. ${ }^{9}$ also showed in their study that these factors did not increase the risk of urethral stricture.

Some studies argued that the risk of developing urethral stricture is higher with BTURP than with monopolar TURP (MTURP) $)^{12-14,15}$. These studies concluded that the high rate of stricture with BTURP is associated with higher energy use, larger diameter of the resectoscope, and longer operation time. Contrary to these studies, there are also studies showing that there is a similar risk of urethral stricture in both methods (monopolar/bipolar) ${ }^{16,17}$. We could not make this comparison as we applied BTURP to all of our patients and we used $26 \mathrm{~F}$ resectoscope and firm energy $(160 \mathrm{~W} / 80 \mathrm{~W})$. In addition, we could not examine the effect of postoperative urethral catheter size on the development of urethral stricture as we inserted a $20 \mathrm{~F}$ or $22 \mathrm{~F}$ three-way Foley urethral catheter to all patients.

In this study, we observed that $46 \%(6 / 13)$ of the strictures developed in the bulbar urethra. Komura et al. ${ }^{11}$ also showed in their study that urethral stricture mostly developed in the bulbar urethra. In this study, we found that postoperative UTI did not increase the risk of urethral stricture. This could be due to the early diagnosis and treatment of postoperative UTI. As a result, the UTI is short time and the fibroblast activity may not be excessive due to this. Tao et al..$^{20}$ showed that postoperative UTI increased the risk of urethral stricture.

Considering the perioperative complications, we did not encounter TUR syndrome or a need for blood transfusion in this study. TUR syndrome and blood transfusion risks were reported in some studies, albeit at a very low rate ${ }^{18,19}$.

In the study by Gilfrich et al. ${ }^{8}$, this rate was reported to be higher $(0.3 \%)$. We did not encounter mortality in our patients within the postoperative 30 days.

When we reviewed those studies, we found that the effects of having a history of preoperative catheter insertion or having a permanent catheter, preoperative WBC count, perioperative NSAID use, and the development of urinary retention after postoperative catheter removal on the development of urethral stricture were not investigated. In this study, we found that a history of preoperative catheter insertion or a permanent catheter $(\mathrm{p}=0.009)$ and a high preoperative WBC count $(\mathrm{p}=0.013)$ increased the risk of urethral stricture. However, we found that the use of perioperative NSAIDs did not affect urethral stricture $(\mathrm{p}=0.925)$.

This study has some limitations. The number of patients participated in this study is less. Also, this is a retrospective study. In addition, we could not make energy and larger diameter of 
the resectoscope comparison as we applied BTURP to all of our patients and we used $26 \mathrm{~F}$ resectoscope and firm energy $(160 \mathrm{~W} / 80 \mathrm{~W})$. In addition, we could not examine the effect of postoperative urethral catheter size on the development of urethral stricture as we inserted a $20 \mathrm{~F}$ or $22 \mathrm{~F}$ three-way Foley urethral catheter to all patients.

\section{CONCLUSION}

BTURP is a reliable method. However, second TURP surgery, having a preoperative permanent catheter or catheter insertion history, high preoperative WBC $\left(10^{3}\right)$ count, and long postoperative catheterization time, increase the risk of urethral stenosis after BTURP.

\section{REFERENCES}

1. Ho HSS, Cheng CWS. Bipolar transurethral resection of prostate: a new reference standard? Curr Opin Urol. 2008;18(1):50-5. https://doi.org/10.1097/MOU.0b013e3282f194db

2. Smith D, Khoubehi B, Patel A. Bipolar electrosurgery for benign prostatic hyperplasia: transurethral electrovaporization and resection of the prostate. Curr Opin Urol. 2005;15(2):95-100. https://doi.org/10.1097/01.mou.0000160623.13366.e8

3. Mamoulakis C, Schulze M, Skolarikos A, Alivizatos G, Scarpa RM, Rassweiler JJ, et al. Midterm results from an international multicentre randomised controlled trial comparing bipolar with monopolar transurethral resection of the prostate. Eur Urol. 2013;63(4):667-76. https://doi.org/10.1016/j.eururo.2012.10.003

4. Madersbacher S, Marberger M. Is transurethral resection of the prostate still justified? BJU Int. 1999;83(3):227-37. https://doi. org/10.1046/j.1464-410x.1999.00908.x

5. Ahyai SA, Gilling P, Kaplan SA, Kuntz RM, Madersbacher S, Montorsi $F$, et al. Meta-analysis of functional outcomes and complications following transurethral procedures for lower urinary tract symptoms resulting from benign prostatic enlargement. Eur Urol. 2010;58(3):384-97. https://doi.org/10.1016/j.eururo.2010.06.005

6. Rassweiler J, Teber D, Kuntz R, Hofmann R. Complications of transurethral resection of the prostate (TURP)-incidence, management, and prevention. Eur Urol. 2006;50(5):969-80. https://doi.org/10.1016/j.eururo.2005.12.042

7. Tan GH, Shah SA, Ali NM, Goh EH, Singam P, Ho CCK, etal. Urethral strictures after bipolar transurethral resection of prostate may be linked to slow resection rate. Investig Clin Urol. 2017;58(3):18691. https://doi.org/10.4111/icu.2017.58.3.186

8. Gilfrich C, Leicht H, Fahlenbrach C, Jeschke E, Popken G, Stolzenburg $J U$, et al. Morbidity and mortality after surgery for lower urinary tract symptoms: a study of 95577 cases from a nationwide German health insurance database. Prostate Cancer Prostatic Dis. 2016;19(4):406-11. https://doi.org/10.1038/pcan.2016.33

9. Kumar BN, Srivastava A, Sinha T. Urethral stricture after bipolar transurethral resection of prostate - truth vs hype: a randomized controlled trial. Indian J Urol. 2019;35(1):41-7. https://doi. org/10.4103/iju.IJU_223_18

10. Aydemir H, Sağlam HS, Köse O, ErdikA, Halis F, Gökçe A. The effect of recurrent direct vision internal urethrotomy for short anterior

\section{ETHICAL APPROVAL}

All procedures performed in studies involving human participants were in accordance with the ethical standards of the Institutional Research Committee and with the 1964 Helsinki Declaration and its later amendments or comparable ethical standards. Written informed consent was obtained from all patients who participated in this study.

\section{AUTHORS' CONTRIBUTIONS}

FA: Conceptualization, Data curation, Formal analysis, Investigation, Methodology, Project administration, Resources, Software, Validation, Visualization, Writing - original draft, Writing review \& editing; FA, OU: Funding acquisition; OU: Supervision.

urethral strictures on the disease course and the predictors of treatment failure. Can Urol Assoc J. 2019;13(11):E366-70. https:// doi.org/10.5489/cuaj.5754

11. Komura K, Inamoto T, Takai T, Uchimoto T, Saito K, Tanda N, et al. Incidence of urethral stricture after bipolar transurethral resection of the prostate using TURis: results from a randomised trial. BJU Int. 2015;115(4):644-52. https://doi.org/10.1111/ bju.12831

12. Tefekli A, Muslumanoglu AY, Baykal M, Binbay M, Tas A, Altunrende F. A hybrid technique using bipolar energy in transurethral prostate surgery: a prospective, randomized comparison. J Urol. 2005;174(4 Pt 1):1339-43. https://doi.org/10.1097/01. ju.0000173075.62504.73

13. Erturhan S, Erbagci A, Seckiner I, Yagci F, Ustun A. Plasmakinetic resection of the prostate versus standard transurethral resection of the prostate: a prospective randomized trial with 1-year follow-up. Prostate Cancer Prostatic Dis. 2007;10(1):97-100. https://doi. org/10.1038/sj.pcan.4500907

14. Seckiner I, Yesilli C, Akduman B, Altan K, Mungan NA. A prospective randomized study for comparing bipolar plasmakinetic resection of the prostate with standard TURP. Urol Int. 2006;76(2):139-43. https://doi.org/10.1159/000090877

15. Nuhoğlu B, Ayyildiz A, Karagüzel E, Cebeci O, Germiyanoğlu C. Plasmakinetic prostate resection in the treatment of benign prostate hyperplasia: results of 1-year follow up. Int J Urol. 2006;13(1):21-4. https://doi.org/10.1111/j.1442-2042.2006.01218.x

16. Autorino R, Damiano R, Di Lorenzo G, Quarto G, Perdonà S, D'Armiento M, et al. Four-year outcome of a prospective randomised trial comparing bipolar plasmakinetic and monopolar transurethral resection of the prostate. Eur Urol. 2009;55(4):922-9. https://doi. org/10.1016/j.eururo.2009.01.028

17. Bhansali M, Patankar S, Dobhada S, Khaladkar S. Management of large (>60 g) prostate gland: PlasmaKinetic Superpulse (bipolar) versus conventional (monopolar) transurethral resection of the prostate. J Endourol. 2009;23(1):141-5. https://doi.org/10.1089/ end.2007.0005

18. Mamoulakis C, Ubbink DT, de la Rosette JJ. Bipolar versus monopolar transurethral resection of the prostate: a systematic review and meta-analysis of randomized controlled trials. Eur Urol. 2009;56(5):798-809. https://doi.org/10.1016/j. eururo.2009.06.037 
19. Huang $X$, Wang L, Wang $X-H$, Shi H-B, Zhang X-J, Yu Z-Y. Bipolar transurethral resection of the prostate causes deeper coagulation depthand less bleeding than monopolar transurethral prostatectomy. Urology 2012;80(5):1116-20. https://doi.org/10.1016/j. urology.2012.07.024

20. Tao H, Jiang YY, Jun Q, Ding X, Jian DL, Jie D, et al. Analysis of risk factors leading to postoperative urethral stricture and bladder neck contracture following transurethral resection of prostate. Int Braz J Urol. 2016;42(2):302-11. https://doi.org/10.1590/ S1677-5538.IBJU.2014.0500
21. Sarier M, Tekin S, Duman ?, Yuksel Y, Demir M, Alptekinkaya F, et al. Results of transurethral resection of the prostate in renal transplant recipients: a single center experience. World J Urol. 2018;36(1):99-103. https://doi.org/10.1007/s00345-0172094-5

22. Sarier M, Duman I, Kilic S, Yuksel Y, Demir M, Aslan M, et al. Comparative Results of Transurethral Incision with Transurethral Resection of The Prostate in Renal Transplant Recipients with Benign Prostate Hyperplasia. Urol J. 2018;15(4):209-13. https:// doi.org/10.22037/uj.vOi0.4074 